\title{
Break the Resistance to Fuel Metabolism: A Long Journey with Bright Future
}

\section{Hong Wang*}

Division of Endocrinology and Metabolism, Department of Internal Medicine, University of Virginia Health System, Charlottesville, VA 22908, USA

*Corresponding author: Division of Endocrinology and Metabolism, Department of Internal Medicine, University of Virginia Health System, Charlottesville, VA 22908, USA, Tel: +434-982-0173; E-mail: Hw8t@virginia.edu

Received date: Jun 23, 2016; Accepted date: Jun 24, 2016; Published date: Jun 27, 2016

Copyright: (c) 2016 Wang H. This is an open-access article distributed under the terms of the Creative Commons Attribution License, which permits unrestricted use, distribution, and reproduction in any medium, provided the original author and source are credited.

Citation: Wang H (2016) Break the Resistance to Fuel Metabolism: A Long Journey with Bright Future. J Metabolic Synd 5: 211. doi:10.4172/ 2167-0943.1000e118

\section{Editor Note}

Metabolic syndrome is characterized by systemic insulin resistance that impairs the ability of insulin to regulate fuel (such as glucose and fat) metabolism. This syndrome has become a global epidemic problem with estimates of prevalence ranging from 20 to $40 \%$ in different populations and has been recognized as a powerful risk factor for the development of cardiovascular disease and type 2 diabetes. Thus, effectively fighting this disastrous health problem is a matter of utmost urgency. To fulfill this mission, our journal, Journal of Metabolic Syndrome, started its long journey in early 2012. Since then, we have set up the scope to publish the most exciting original research articles and reviews on metabolic syndrome with the purpose to facilitate the research and teaching and to provide reference for this field. So far, we have made a great progress and have successfully published 5 volumes with 18 regular issues plus additional special issues. The valuable information from these published articles has become the important resource for researchers and clinicians to fight and eventually to conquer this syndrome.

In this issue of Journal of Metabolic Syndrome, an intriguing study by de Luis et al. suggests an association between a single nucleotide polymorphism of cannabinoid receptor gene Type 2 gene and metabolic response to the a Mediterranean hypocaloric diet-induced weight loss. The results show that non minor allele carriers have a better improvement in all metabolic variables and pro-inflammative markers measured in the study after the weight loss than minor allele carriers.

Another clinical study in this issue by Sanai et al. indicates that compared to the treatment with fat-soluble statins, either atorvastatin or pitavastatin, treatment of the dyslipidemia using water-soluble statin, pravastatin, in the end-stage renal disease patients on maintenance of hemodialysis better improves patients' lipid profile and other metabolic variables.

Also in this issue of Journal of Metabolic Syndrome, a comprehensive epidemiological study by Miller reported the data of total 9326 subjects derived from 6 national survey cohorts in the United States from 2001-2012. This survey has suggested that waist circumference and triglycerides are the risk factors with the highest prevalence for the development of metabolic syndrome.

Much more exciting research articles and reviews can be found in our online journal archive. We very welcome more and more researchers/authors to contribute their manuscripts to our journal and highly expect more and more readers follow our journal with great interest. Let us work together to make our journal constant success. 